\title{
The Effect of Annealing Temperature on Spin- Coated Zn-doped NiO Film for Humidity Sensing Applications
}

\author{
N.F.Q. Fahmi, M.H. Mamat, N. Parimon, A.S. Zoolfakar, A.H.A. Razak, I.B. Shameem Banu, and M.Rusop
}

\begin{abstract}
Zinc (Zn)-doped nickel oxide (NiO) thin films were fabricated using spin coating technique for humidity sensing applications. Nickel acetate tetrahydrate was used as a precursor material and zinc acetate was used as the dopant source. The films were annealed at various annealing temperatures of $400{ }^{\circ} \mathrm{C}, 500{ }^{\circ} \mathrm{C}$ and $550{ }^{\circ} \mathrm{C}$ in ambient. $\mathrm{X}$-ray diffraction (XRD) was used to investigate the structural properties of the samples, while ultravioletvisible spectroscopy (UV-Vis) was used to characterize the optical properties of the samples. The thickness of the samples was measured using a surface profiler which the thickness are $178.8 \mathrm{~nm}$, $148.0 \mathrm{~nm}$, and $116.9 \mathrm{~nm}$ for samples annealed at $400{ }^{\circ} \mathrm{C}, 500{ }^{\circ} \mathrm{C}$ and $550^{\circ}$, respectively. The humidity sensing properties for each sample were characterized using humidity chamber equipped with humidity sensing measurement system which the relative humidity $(R H)$ value was set between $40 \% R H$ and $90 \% R H$. The XRD results showed that all samples were in the amorphous state. The average transmittance in the visible region obtained from the $U V$-vis spectra exceeded $90 \%$ transmission for all samples. The highest bandgap obtained is $3.6 \mathrm{eV}$ for $\mathrm{Zn}$-doped $\mathrm{NiO}$ annealed at $500{ }^{\circ} \mathrm{C}$. The humidity sensing results show that a high sensitivity sensor could be produced using sample annealed at $550^{\circ} \mathrm{C}$.
\end{abstract}

Keywords: Zn doped NiO; spin coating technique; humidity sensing properties.

\section{INTRODUCTION}

Accurate humidity sensors particularly those that are prepared using facile and low-cost fabrication processes are important for humidity monitoring in several fields including medical, storage, semiconductor industries, agriculture, textile industries, and environment $[1,2]$. The humidity sensing characteristics are analyzed through their signal change when the incidence of water vapour absorption occurs on the sensing surface. There are few types of techniques used to design humidity sensor which are resistivity, acoustic, mechanical, capacitive, and optical techniques. However, most of the research regarding the humidity sensor targeting a new material.

This manuscript is submitted on 22 December 2019 and accepted on 2 May 2020.

N.F.Q. Fahmi, N. Parimon, M. H. Mamat, A. S. Zoolfakar, A.H.A. Razak and M. Rusop are from Faculty of Electrical Engineering, Universiti Teknologi MARA (UiTM), 40450 Shah Alam, Selangor, Malaysia (e-mail: mhmamat@uitm.edu.my).

I. B. Shameem Banu is from School of Physical and Chemical Sciences, B.S. Abdur Rahman Crescent Institute of Science \& Technology, Vandalur, Chennai 600 048, India.

1985-5389/C 2021 The Authors. Published by UiTM Press. This is an open access article under the CC BY-NC-ND license (http://creativecommons.org/ licenses/by-nc-nd/4.0/).
Material engineering of the sensing layer, which focus on novel morphologies, also conducted to improve the humidity sensing properties and response time. Moisture and humidity are the terms that commonly used to represent water contents. It is important to precisely measure the water content in a different environment with different processes because even a small amount of water content can easily affect the physical and chemical nature of materials [3].

To date, the applications of high-quality humidity sensors are essential in various field. Humidity sensors are used in semiconductor industries to monitor the wafer processing areas [4]. Next, human breathing can be monitored by using humidity sensor in the medical sector [5-10]. By monitoring and detecting the abnormal respiratory rate, some major diseases could be diagnosed [11]. Some respiratory disorders and failures could be identified by monitoring breathing airflows such as apnoea and hypopnoea [12]. In agriculture sectors, the crop growth was monitored using humidity sensors [13]. The collected data from humidity sensors are directly transferred to the central control system via wireless network technology.

A reliable production method, low-cost preparation, and low-cost material but producing excellent humidity sensing performance are preferable for mass production. Considering these factors, this research provides a path towards achieving those components and at the same time improving the commercially available products. In this research, a simple method called a sol-gel spin coating technique was used to fabricate humidity sensors based on zinc $(\mathrm{Zn})$ doped nickel oxide (NiO). Aside from low-temperature fabrication, these humidity sensors also operate well at room temperature without any external heating, which normally used to enhance humidity detection.

$\mathrm{NiO}$ materials have a wide range of energy bandgap from $3.6 \mathrm{eV}$ to $4.0 \mathrm{eV}$ with a simple cubic structure. Therefore, it is widely used in many applications such as transparent electrodes in photovoltaic devices. The advantages feature of $\mathrm{NiO}$ are it is a p-type and low-cost material. $\mathrm{NiO}$ also is known for its strong durability, large span optical density, promising ion storage materials in terms of cyclic stability, electrochemical stability, and many techniques can be used to manufacture $\mathrm{NiO}$ [14]. Due to $\mathrm{NiO}$ good responsivity, it can be used as a touch screen, photodetector, and it also can be used as a gas sensor because of its bandgap [15]. Other than that, $\mathrm{NiO}$ has great potential when it comes for applications in wide electromagnetics absorbers, packaging materials, wastewater catalyst, and batteries. These applications could be improved when the $\mathrm{NiO}$ doped with certain metals or it is mixed with metal oxides or 
polymer to produce composite. There are many reports available regarding lithium (Li) or cobalt $(\mathrm{Co})$ doped $\mathrm{NiO}$, however, there are less exploration on $\mathrm{Zn}$-doped $\mathrm{NiO}$ [16]. The present study on $\mathrm{Zn}$-doped $\mathrm{NiO}$ for humidity sensing can open a new insight of p-type material for humidity sensor applications.

It is proven that the sol-gel process is a useful approach for the researchers to prepare various materials. There are many experimental results showed that this method was suitable and successful to produce material on a large scale. Besides, the solgel method is frequently utilized to synthesize organic or inorganic hybrid nanocomposites as it can be performed under ambient condition [17]. The sol-gel method is an important process in semiconductor technology because it can produce high-quality thin films $[18,19]$. This technology has excellent control of stoichiometry and composition modification, therefore it probably can offer to manufacture a large scale of high quality homogenous thin films using inexpensive equipment that can lead to a cost-effective process [19].

Herein, we prepared the $\mathrm{Zn}$-doped $\mathrm{NiO}$ films via sol-gel spin-coating technique for humidity sensing applications. The prepared samples show promising results as its response well with the humidity.

\section{Methodology}

Preparation of $\mathrm{Zn}$-doped $\mathrm{NiO}$ thin films was shown in Figure 1. The solution was deposited onto the glass substrate using the spin coating technique. The films were then undergone drying process at $250{ }^{\circ} \mathrm{C}$ before it was annealed in a furnace at various temperatures of $400^{\circ} \mathrm{C}, 500^{\circ} \mathrm{C}$, and $550^{\circ} \mathrm{C}$. The thin films were then undergone the characterization process.

\subsection{Solution preparation for Zn-doped NiO}

$\mathrm{Zn}$-doped $\mathrm{NiO}$ thin films were produced using the sol-gel spin coating method. First, the precursor solution was prepared using $2.4884 \mathrm{~g}$ of nickel acetate powder, $0.1103 \mathrm{~g}$ zinc acetate dihydrate powder and $2 \mathrm{ml}$ diethanolamine in $50 \mathrm{ml}$ ethylene glycol monoethyl ether. The prepared solution was then sonicated for half an hour at $50{ }^{\circ} \mathrm{C}$ by using sonication bath. After the solution was sonicated, the hotplate magnetic stirrer was used to stir the solution for 1 hour at room temperature.

\subsection{Deposition of Thin Film Using Spin Coating Technique}

Spin coating method was used to deposit the thin films onto the glass substrate for each sample. The speed of spin coater (Laurell WS 650) was set at $4000 \mathrm{rpm}$ for 60 seconds. The precursor was dropped onto the glass substrate using pipette during rotation of the spin coater. The sample was then undergone the drying process using a furnace for 5 minutes at $250{ }^{\circ} \mathrm{C}$. The dropping precursor and drying process were repeated 5 times to increase the thickness of the thin film.

\subsection{Annealing Process}

The samples were annealed at various temperatures of 400 ${ }^{\circ} \mathrm{C}, 500^{\circ} \mathrm{C}$, and $550^{\circ} \mathrm{C}$ using the furnace for two hours.

\subsection{Metal Contact Deposition}

Thermal evaporation technique (Ulvac-VPC-1100) was used to deposited silver $(\mathrm{Ag})$ with a thickness of $60 \mathrm{~nm}$ as a metal contact on the glass substrate

\subsection{Characterization Process}

The crystallinity behaviour of each sample was characterized using X-ray diffraction (XRD, PANalytical X'Pert PRO). The optical properties of the samples were investigated using ultraviolet-visible (UV-Vis) spectroscopy (Jusco). Next, the samples were characterized using the humidity sensor measurement system to study the humidity sensing performance of the samples. In this measurement, a humidity chamber (Espec) was used with the sensor measurement unit (Keithley 2400) and software. The relative humidity (RH) in the humidity chamber was set between $40 \% \mathrm{RH}$ to $90 \% \mathrm{RH}$. The thickness of the samples was measured using the surface profiler (KLA Tencor P-6).

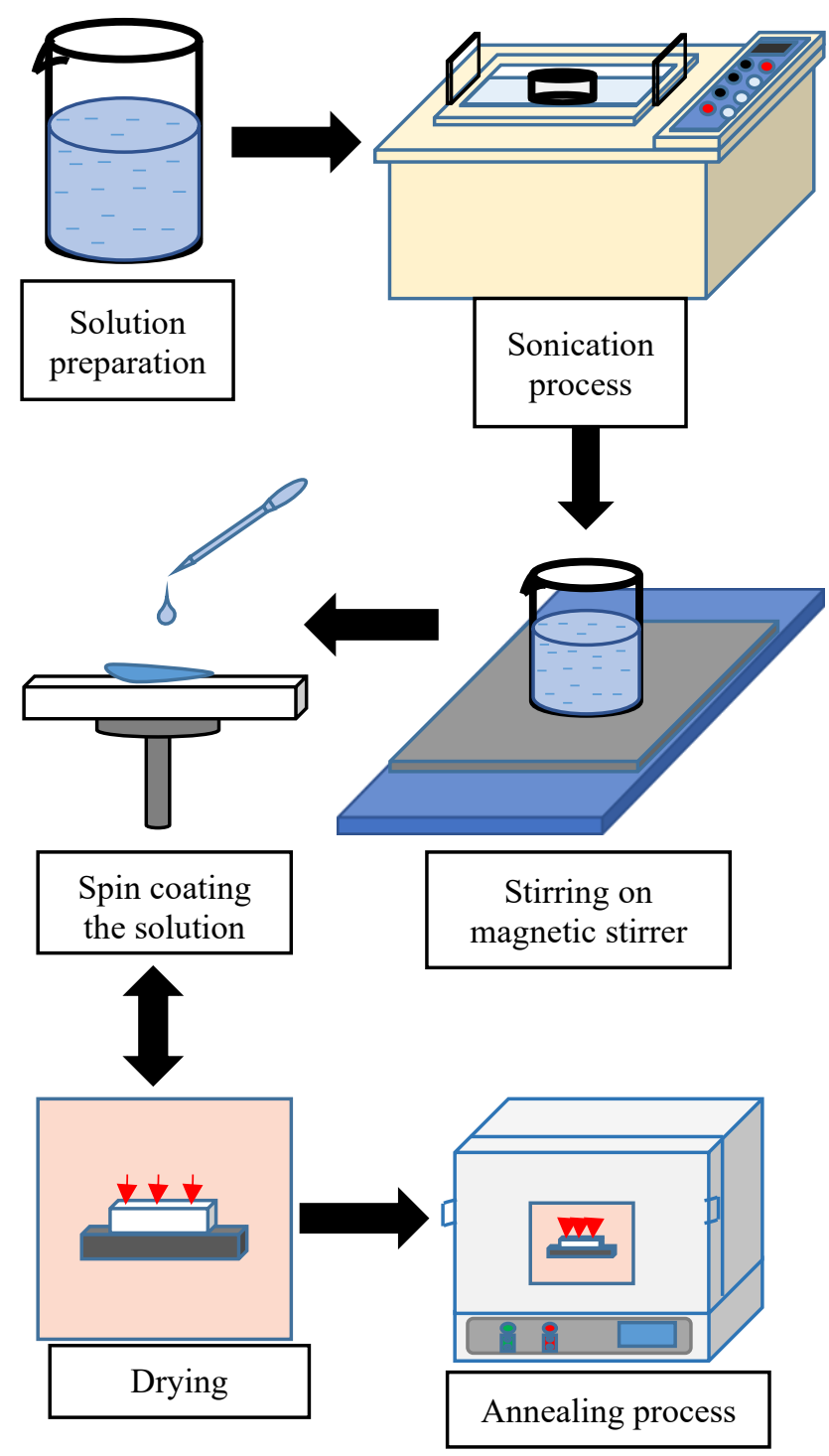

Fig. 1: Preparation of Zn-doped $\mathrm{NiO}$ thin films 


\section{RESULTS}

\subsection{Structural properties}

XRD characterization was conducted to investigate the crystallinity of $\mathrm{Zn}$-doped $\mathrm{NiO}$ at various annealing temperatures of $400{ }^{\circ} \mathrm{C}, 500{ }^{\circ} \mathrm{C}$, and $550{ }^{\circ} \mathrm{C}$. From the XRD pattern in Figure 2, it can be seen that the XRD result for $\mathrm{Zn}$ doped $\mathrm{NiO}$ films annealed at different temperatures have amorphous structures. There is only one peak appeared in the XRD pattern located at $42.6^{\circ}$, which corresponded to (200) plane. However, this peak exhibits broad and weak XRD intensity to indicate the poor crystallinity structure for all samples. This peak gradually diminished after annealed at high temperature, which might be due to the activation of dopant into $\mathrm{NiO}$ lattice. At high annealing temperature, the $\mathrm{Zn}$ dopant has sufficient energy to integrate into $\mathrm{NiO}$ lattice and creates structural defects, which transforms $\mathrm{NiO}$ into amorphous phase. This condition also occurs due to the crystallite structure of $\mathrm{Zn}$ doped $\mathrm{NiO}$ is not well-built. It also could be observed in the XRD patterns for all samples that there is wide diffraction peak from $20^{\circ}$ to $40^{\circ}$ which represents the amorphous phase of the glass substrate $[20,21]$. The result obtained from the XRD graph is contradicted with the study made by N. Parimon et al. [22] which reported that the peak of $\mathrm{NiO}$ is narrower when the annealing temperature increased. However, they studied on the nanostructured $\mathrm{NiO}$, which prepared using immersion method and may have different $\mathrm{NiO}$ characteristics to that of the granular film prepared using sol-gel spin-coating method. In addition, the optimized annealing temperature for different materials might be varied depending on the annealing equipment, substrate, preparation process and others. Our results in Figure 2 shows that the high crystallization of $\mathrm{Zn}$ doped $\mathrm{NiO}$ samples could not be detected and the films only exhibit amorphous characteristics. The amorphous structure or incomplete crystallinity of $\mathrm{Zn}$-doped $\mathrm{NiO}$ occurs due to the appalling desorption of oxygen molecules in the precursor [23]. Martínez-Gil et al. prepared undoped $\mathrm{NiO}$ thin film using chemical water bath deposition at different annealing temperatures between $200{ }^{\circ} \mathrm{C}$ to $400{ }^{\circ} \mathrm{C}$ [24]. They found that the diffraction peak with very low intensity only appeared after annealing process at $400{ }^{\circ} \mathrm{C}$. However, the reduce in the peak intensity is commonly reported after doping with metal elements[25].

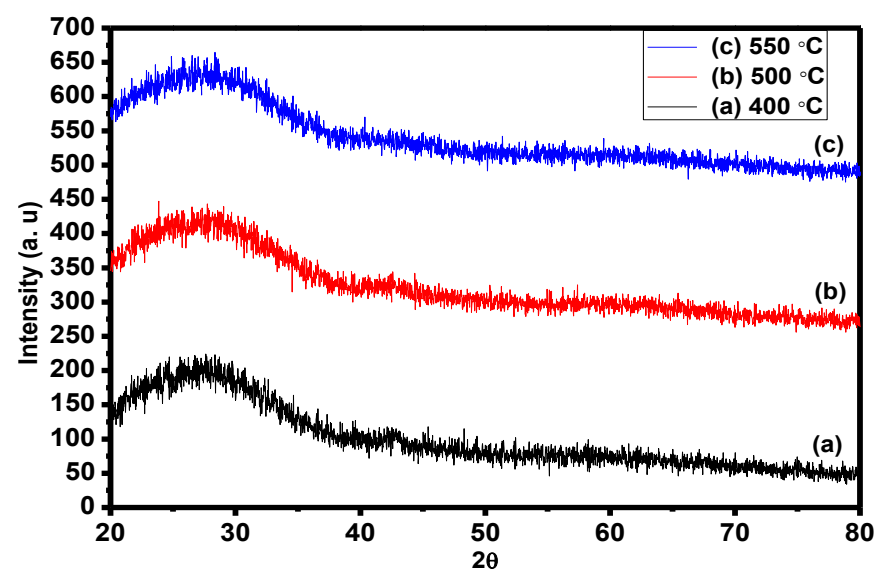

Fig. 2: XRD patterns for $\mathrm{Zn}$-doped $\mathrm{NiO}$ at different annealing temperatures

\subsection{Optical properties}

The optical properties of $\mathrm{Zn}$-doped $\mathrm{NiO}$, which are characterized through transmittance and absorbance spectra in the wavelength regions between $300 \mathrm{~nm}-800 \mathrm{~nm}$ is presented in Figures 3 and 4, respectively. The average transmittance of the samples was calculated between $400 \mathrm{~nm}$ and $800 \mathrm{~nm}$ and the data were tabulated in Table 1 . Based on Table 1, the average transmittance values for all samples exceed $90 \%$. Specifically, the transmittance values are $91.5 \%, 90.4 \%$ and $92.9 \%$ for $\mathrm{Zn}$-doped $\mathrm{NiO}$ films at annealing temperatures of $400{ }^{\circ} \mathrm{C}, 500{ }^{\circ} \mathrm{C}$, and $550{ }^{\circ} \mathrm{C}$ respectively. These results suggested that the transmittance value for all samples are almost constant despite the difference in the annealing temperatures.

TABLE 1: AVERAGE TRANSMITTANCE AND BAND GAP VALUE FOR ZN-DOPED NIO AT DIFFERENT ANNEALING TEMPERATURES

\begin{tabular}{ccc}
\hline \hline $\begin{array}{c}\text { Annealing temperature } \\
\left({ }^{\circ} \mathrm{C}\right)\end{array}$ & $\begin{array}{c}\text { Average } \\
\text { transmittance } \\
(\%)\end{array}$ & $\begin{array}{c}\text { Bandgap } \\
(\mathrm{eV})\end{array}$ \\
\hline 400 & 91.5 & 3.42 \\
500 & 90.4 & 3.60 \\
550 & 92.9 & 3.58 \\
\hline \hline
\end{tabular}

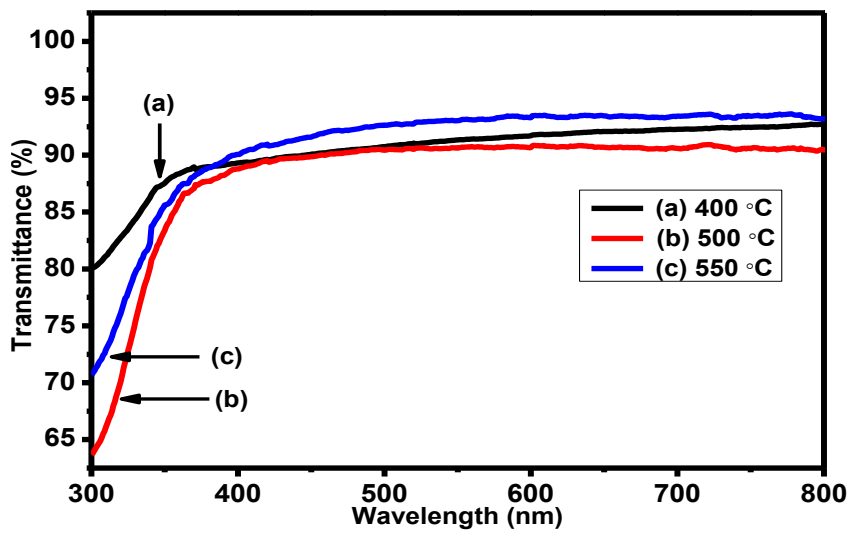

Fig. 3: Transmittance graph for $\mathrm{Zn}$-doped $\mathrm{NiO}$ at different annealing temperatures

Figure 4 presents the absorbance spectra of $\mathrm{Zn}$-doped $\mathrm{NiO}$ at annealing temperature varied at $400{ }^{\circ} \mathrm{C}, 500{ }^{\circ} \mathrm{C}$, and $550{ }^{\circ} \mathrm{C}$. Higher absorbance value can be seen in the lower wavelength in Figure 4, which indicates that all samples exhibit high UV absorption at wavelength below $400 \mathrm{~nm}$ [26]. 


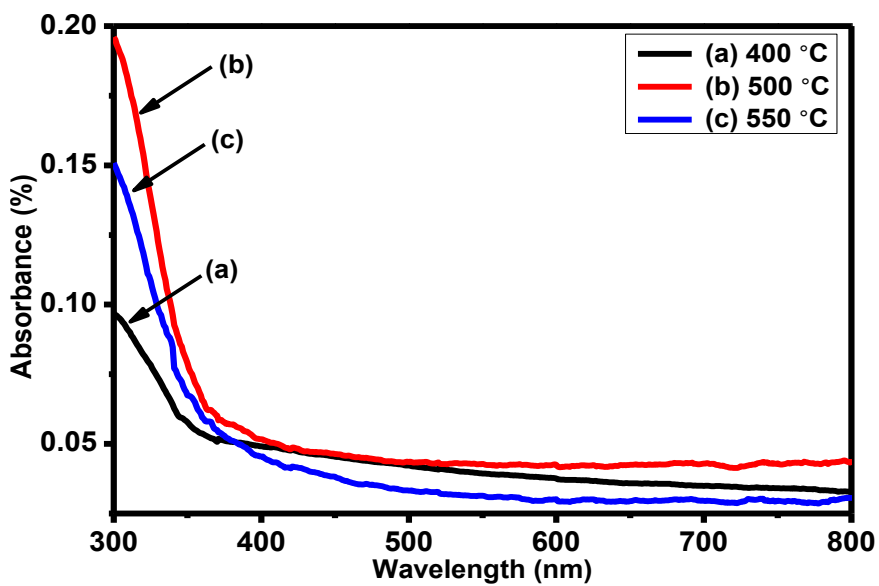

Fig. 4: The absorbance of $\mathrm{Zn}$-doped $\mathrm{NiO}$ at different annealing temperatures

The thickness of thin films was measured using the surface profiler (KLA Tencor P-6). Figure 5 shows the thickness graph obtained from the surface profiler for the sample annealed at $400{ }^{\circ} \mathrm{C}$. The "St height" shown in Figure 5 indicates the thickness value of the film which is $178.8 \mathrm{~nm}$. The thickness for the sample annealed at $500{ }^{\circ} \mathrm{C}$ and $550{ }^{\circ} \mathrm{C}$ are $148.0 \mathrm{~nm}$ and $116.9 \mathrm{~nm}$ respectively. The result shows that the thickness of the film reduces at higher annealing temperature due to densification of the grain.

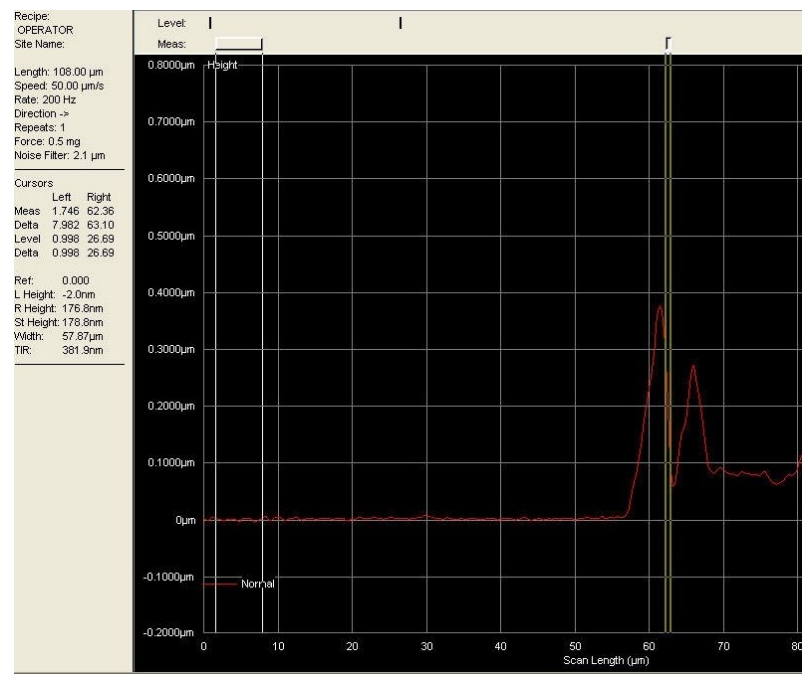

Fig. 5: Thickness measurement result for the sample annealed at $400{ }^{\circ} \mathrm{C}$

Next, the optical band gap values of the samples were calculated using Tauc's plot relation based on the following equation (1):

$\alpha h v=B\left(h v-E_{g}\right)^{1 / 2}$

where $E_{g}$ act as the optical band gap, $B$ is constant, $\alpha$ is the absorption coefficient, and $h v$ is photon energy. The Tauc's plot of $\mathrm{Zn}$ doped $\mathrm{NiO}$ at different annealing temperatures of 400 ${ }^{\circ} \mathrm{C}, 500{ }^{\circ} \mathrm{C}$, and $550{ }^{\circ} \mathrm{C}$ are presented in Figure 6 . The bandgap values were retrieved from the intercept at the $\mathrm{x}$-axis of the plot and were tabulated in Table 1. The estimated values obtained from the intercept at the $\mathrm{x}$-axis are $3.42 \mathrm{eV}, 3.6 \mathrm{eV}$, and 3.58
$\mathrm{eV}$ for $400{ }^{\circ} \mathrm{C}$-, $500{ }^{\circ} \mathrm{C}$-, and $550{ }^{\circ} \mathrm{C}$-annealed $\mathrm{Zn}$-doped $\mathrm{NiO}$ films, respectively.

Previous studies indicate that when annealing temperature increases, the value of the bandgap also increases [27, 28]. The bandgap values obtained from this study are still in good agreement with the reported band gap values of $3.15-3.80 \mathrm{eV}$ for $\mathrm{NiO}$ thin films [29].

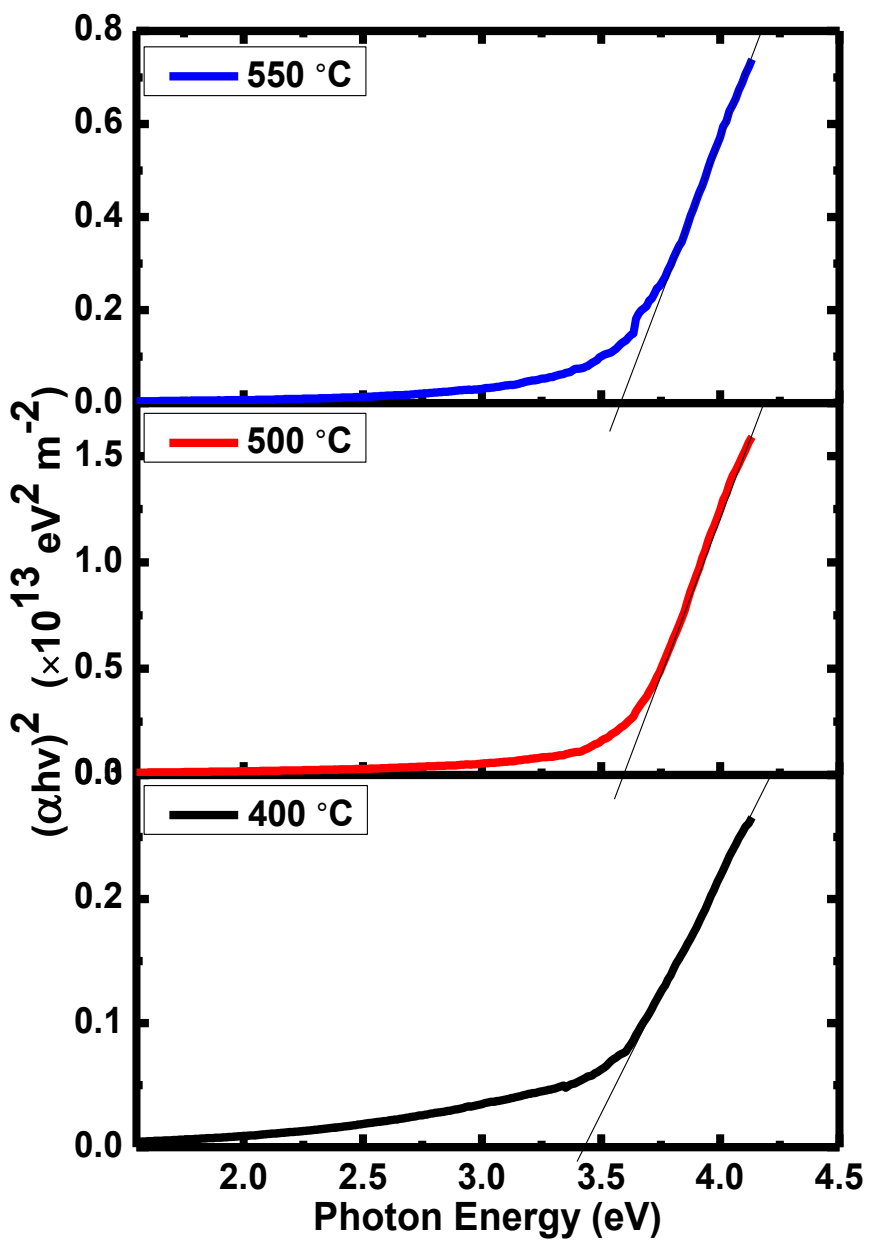

Fig. 6: Estimation of bandgap energy of $\mathrm{Zn}$ doped $\mathrm{NiO}$ at various annealing temperature by using Tauc's plot.

\subsection{Humidity sensing properties}

The humidity responses for $\mathrm{Zn}$-doped $\mathrm{NiO}$ films were measured using the humidity sensor measurement system with humidity chamber. The sensing response represents by the current (I) versus time (t) plots, as shown in Figures 7. Measurements were conducted in a humidity chamber with the values of humidity level ranged between $40 \% \mathrm{RH}$ to $90 \% \mathrm{RH}$. The bias voltage used to measure the humidity on the samples was fixed at $5 \mathrm{~V}$ in room temperature. The value of humidity level was changed from $40 \% \mathrm{RH}$ to $90 \% \mathrm{RH}$ and from $90 \% \mathrm{RH}$ to $40 \% \mathrm{RH}$ to characterize one cycle sensing response towards increasing and decreasing condition of relative humidity percentage.

The plot of humidity response at different humidity levels for $\mathrm{Zn}$-doped $\mathrm{NiO}$ films annealed at temperatures of $400{ }^{\circ} \mathrm{C}, 500$ ${ }^{\circ} \mathrm{C}$, and $550{ }^{\circ} \mathrm{C}$ are represented in Figure 7. The humidity response plot shows that all samples exhibit increased values of the current signal at the increasing $\mathrm{RH}$ values from $40 \% \mathrm{RH}$ to $90 \%$ RH. The $\mathrm{Zn}$-doped NiO films annealed at $500{ }^{\circ} \mathrm{C}$ and 550 
${ }^{\circ} \mathrm{C}$ show slightly stable current responses when the $\mathrm{RH}$ values were varied from $40 \% \mathrm{RH}$ to $90 \% \mathrm{RH}$ and show a smooth current response when the RH values decreased from $90 \% \mathrm{RH}$ to $40 \% \mathrm{RH}$. However, the humidity sensing graph for $400{ }^{\circ} \mathrm{C}$ annealed film shows a slight deteriorated current signal at the increasing RH levels. This deteriorated signal for $400{ }^{\circ} \mathrm{C}$ annealed films is poorer than that of the response current signals of the samples annealed at $500{ }^{\circ} \mathrm{C}$ and $550{ }^{\circ} \mathrm{C}$. The current signals for all samples gradually decrease when the humidity level is reduced from $90 \% \mathrm{RH}$ to $40 \% \mathrm{RH}$. The humidity sensitivity was calculated for each sample to be $105.5,45.8$, and 107.7 for $\mathrm{Zn}$-doped $\mathrm{NiO}$ annealed at $400{ }^{\circ} \mathrm{C}, 500{ }^{\circ} \mathrm{C}$, and 550 ${ }^{\circ} \mathrm{C}$, respectively. The $\mathrm{Zn}$-Doped $\mathrm{NiO}$ film annealed at $550^{\circ} \mathrm{C}$ shows the highest sensitivity followed by $400{ }^{\circ} \mathrm{C}$ and $500{ }^{\circ} \mathrm{C}$ annealed samples. The sensitivity values of the humidity sensing were calculated using equation (2).

$S=\frac{I_{90 \% R H}}{I_{40 \% R H}}$

Here, $\mathrm{I}_{90 \% \mathrm{RH}}$ is the current value at $90 \% \mathrm{RH}$, while $\mathrm{I}_{40 \% \mathrm{RH}}$ is the current value at $40 \% \mathrm{RH}$.

The humidity sensing plot also shows that the current signal for the samples annealed at $550^{\circ} \mathrm{C}$ is higher compared to other samples. This condition might be due to the surface of $\mathrm{Zn}$ doped $\mathrm{NiO}$ film at an annealing temperature of $550{ }^{\circ} \mathrm{C}$ can adsorb more water molecules, which enhances the movement of the ions in the film that converted into high current signals. Water molecules react with the sensors during the increased humidity levels through chemisorption, physisorption and capillary processes of the water molecules on the film's surface [30], in which the electrolytic and ionic conduction mechanisms are taking place. This mechanisms reduce the resistance of the sensor at the increasing humidity levels and contribute to the sensitivity of the sensor [26]. It should be noted that, the annealing temperature could be increased more if the expensive substrate such as alumina or pure silicon dioxide is used. The melting point of $\mathrm{NiO}$ is approximately $1,955^{\circ} \mathrm{C}$ and therefore the study on annealing temperature below this point and their effects to the humidity sensing performance will provide a new insight into properties of $\mathrm{NiO}$ film.

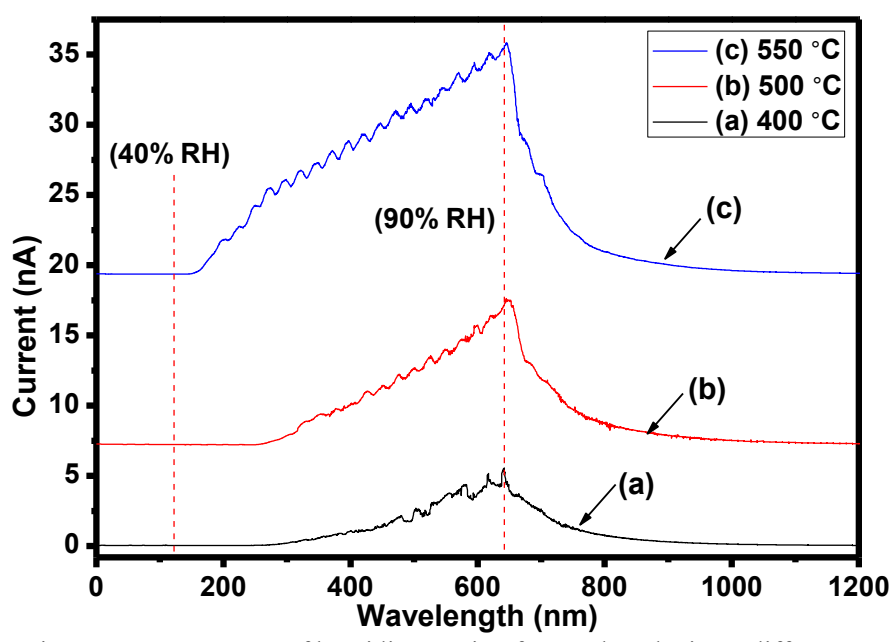

Fig. 7: Response curve of humidity sensing for $\mathrm{Zn}$-doped $\mathrm{NiO}$ at different annealing temperatures

\section{CONCLUSION}

Zn-doped NiO was successfully deposited using spin coating technique and annealed at different temperatures of $400{ }^{\circ} \mathrm{C}, 500$ ${ }^{\circ} \mathrm{C}$, and $550{ }^{\circ} \mathrm{C}$. The structural, optical and humidity sensing properties of the films were investigated. The XRD analysis showed that the prepared samples were amorphous $\mathrm{NiO}$ structures, with only one broad peak with very low intensity was observed in the XRD pattern. The bandgap of the $\mathrm{Zn}$-doped $\mathrm{NiO}$ annealed at $400{ }^{\circ} \mathrm{C}, 500{ }^{\circ} \mathrm{C}$ and $550{ }^{\circ} \mathrm{C}$ samples were 3.42 , 3.60 and 3.58 respectively. The transmittance level for each sample was excellent with the average transmittance value exceeds $90 \%$ for every sample. All samples were responsive towards different range humidity level that varied from $40 \%$ $\mathrm{RH}$ to $90 \% \mathrm{RH}$. Among the samples, sample annealed at 550 ${ }^{\circ} \mathrm{C}$ showed the highest sensitivity with the value of 107.7 , followed by the samples annealed at $500{ }^{\circ} \mathrm{C}$ and $400{ }^{\circ} \mathrm{C}$ with sensitivity values of 105.5 and 45.8 , respectively. These results suggested that the amorphous $\mathrm{Zn}$-doped $\mathrm{NiO}$ thin films have high potential for humidity sensing application with good device performance.

\section{ACKNOWLEDGEMENT}

The authors would like to acknowledge Ministry of Education for the grant given to conduct this project (FRGS 600-IRMI/FRGS 5/3 (044/2019). The authors would like to thank the Faculty of Electrical Engineering and Institute of Research Management \& Innovation (IRMI) of UiTM Shah Alam for their supports of this project.

\section{REFERENCES}

H. Hamouche, S. Makhlouf, A. Chaouchi, and M. Laghrouche, "Humidity Sensor Based on Keratin bio Polymer Film," Sensors and Actuators A: Physical, vol. 282, pp. 132-141, 2018.

T. Yuan, X. Qi, Z. Liu, J. Yang, C. Guan, Q. Long, J. Cao, M. Luo, $\mathrm{X}$. Yang, and L. Yuan, "Humidity sensor based on micro optical fiber array fabricated by electrospinning," Optics Communications, vol. 427, pp. 517-521, 2018.

T. A. Blank, L. P. Eksperiandova, and K. N. Belikov, "Recent trends of ceramic humidity sensors development: A review," Sensors and Actuators B: Chemical, vol. 228, pp. 416-442, 2016.

Z. Chen and C. Lu, "Humidity Sensors: A Review of Materials and Mechanisms," Sensor Letters, vol. 3, pp. 274-295, // 2005.

F. J. Arregui, Y. Liu, I. R. Matias, and R. O. Claus, "Optical fiber humidity sensor using a nano Fabry-Perot cavity formed by the ionic self-assembly method," Sensors and Actuators B: Chemical, vol. 59, pp. 54-59, 10/5/ 1999.

C. Laville, J. Y. Delétage, and C. Pellet, "Humidity sensors for a pulmonary function diagnostic microsystem," Sensors and Actuators B: Chemical, vol. 76, pp. 304-309, 6/1/ 2001.

R. Rimeika, D. Čiplys, V. Poderys, R. Rotomskis, and M. S. Shur, "Fast-response surface acoustic wave humidity sensor based on hematoporphyrin film," Sensors and Actuators B: Chemical, vol. 137 , pp. 592-596, 4/2/ 2009.

S. Akita, H. Sasaki, K. Watanabe, and A. Seki, "A humidity sensor based on a hetero-core optical fiber," Sensors and Actuators B: Chemical, vol. 147, pp. 385-391, 6/3/2010.

A. Tételin, C. Pellet, C. Laville, and G. N'Kaoua, "Fast response humidity sensors for a medical microsystem," Sensors and Actuators B: Chemical, vol. 91, pp. 211-218, 6/1/2003.

J. M. Corres, F. J. Arregui, and I. R. Matías, "Sensitivity optimization of tapered optical fiber humidity sensors by means of 
tuning the thickness of nanostructured sensitive coatings," Sensors and Actuators B: Chemical, vol. 122, pp. 442-449, 3/26/ 2007.

[11] M. Folke, L. Cernerud, M. Ekström, and B. Hök, "Critical review of non-invasive respiratory monitoring in medical care," Medical and Biological Engineering and Computing, vol. 41, pp. 377-383, 2003.

[12] Y. Kang, H. Ruan, Y. Wang, F. J. Arregui, I. R. Matias, and R. O. Claus, "Nanostructured optical fibre sensors for breathing airflow monitoring," Measurement Science and Technology, vol. 17, p. 1207,2006

[13] K. Shinghal, A. Noor, and N. Srivastava, "Intelligent humidity sensor for wireless sensor network agricultural application."

[14] I. Sta, M. Jlassi, M. Hajji, and H. Ezzaouia, "Structural, optical and electrical properties of undoped and Li-doped $\mathrm{NiO}$ thin films prepared by sol-gel spin coating method," Thin Solid Films, vol. 555, pp. 131-137, 2014.

[15] A. Diha, S. Benramache, and B. Benhaoua, "Transparent nanostructured $\mathrm{Co}$ doped $\mathrm{NiO}$ thin films deposited by sol-gel technique," Optik, vol. 172, pp. 832-839, 2018/11/01/2018.

[16] S. Dewan, M. Tomar, R. P. Tandon, and V. Gupta, "Zn doping induced conductivity transformation in $\mathrm{NiO}$ films for realization of p-n homo junction diode," Journal of Applied Physics, vol. 121, p. 215307, 2017.

[17] A. E. Gash, R. L. Simpson, and J. H. Satcher, "Energetic Nanocomposites with Sol-gel Chemistry : Synthesis, Safety , and Characterization," 2002.

[18] T. Ivanova, A. Harizanova, T. Koutzarova, and B. Vertruyen, "Morphological investigation of indium and gallium co-doped $\mathrm{ZnO}$ films, derived by sol-gel method," Proceedings of the International Spring Seminar on Electronics Technology, pp. 1-6, 2017.

[19] H. Y. Yue, E. J. Guo, L. P. Wang, F. W. Kang, Y. K. Guo, and Z. $\mathrm{M}$. Yu, "Preparation of $\mathrm{NiO}$ coated aluminum borate whiskers by a solgel process and an ultrasonic dispersion technique," Proceedings - 2012 7th International Forum on Strategic Technology, IFOST 2012, 2012.

[20] Y. Li, M. Guo, M. Zhang, and X. Wang, "Hydrothermal synthesis and characterization of $\mathrm{TiO} 2$ nanorod arrays on glass substrates," Materials Research Bulletin, vol. 44, pp. 1232-1237, 2009.

[21] M. H. Mamat, M. F. Malek, N. N. Hafizah, M. N. Asiah, A. B. Suriani, A. Mohamed, N. Nafarizal, M. K. Ahmad, and M. Rusop, "Effect of oxygen flow rate on the ultraviolet sensing properties of zinc oxide nanocolumn arrays grown by radio frequency magnetron sputtering," Ceramics International, vol. 42, pp. 4107-4119, 2/15/ 2016.

[22] N. Parimon, M. H. Mamat, A. S. Ismail, I. B. S. Banu, M. K. Ahmad, A. B. Suriani, and M. Rusop, "Influence of Annealing Temperature on The Sensitivity of Nickel Oxide Nanosheet Films in Humidity Sensing Applications," Indonesian Journal of Electrical Engineering and Computer Science, vol. 18, pp. 284-292, 2020.

[23] A. Khayatian, M. A. Kashi, R. Azimirad, S. Safa, and S. F. A Akhtarian, "Effect of annealing process in tuning of defects in $\mathrm{ZnO}$ nanorods and their application in UV photodetectors," Optik, vol. 127, pp. 4675-4681, 2016.

[24] M. Martínez-Gil, M. I. Pintor-Monroy, M. Cota-Leal, D. CabreraGerman, A. Garzon-Fontecha, M. A. Quevedo-López, and M. Sotelo-Lerma, "Influence of annealing temperature on nickel oxide thin films grown by chemical bath deposition," Materials Science in Semiconductor Processing, vol. 72, pp. 37-45, 2017/12/01/ 2017.

[25] M. H. Mamat, N. Parimon, A. S. Ismail, I. B. Shameem Banu, S. Sathik Basha, R. A. Rani, A. S. Zoolfakar, M. F. Malek, A. B. Suriani, M. K. Ahmad, and M. Rusop, "Synthesis, structural and optical properties of mesostructured, X-doped $\mathrm{NiO}(\mathrm{x}=\mathrm{Zn}, \mathrm{Sn}, \mathrm{Fe})$ nanoflake network films," Materials Research Bulletin, vol. 127, p. 110860, 2020/07/01/2020.

[26] A. S. Ismail, M. H. Mamat, N. D. Md. Sin, M. F. Malek, A. S. Zoolfakar, A. B. Suriani, A. Mohamed, M. K. Ahmad, and M. Rusop, "Fabrication of hierarchical Sn-doped $\mathrm{ZnO}$ nanorod arrays through sonicated sol-gel immersion for room temperature, resistive-type humidity sensor applications," Ceramics International, vol. 42, pp. 9785-9795, 2016.

[27] K. Varunkumar, R. Hussain, G. Hegde, and A. S. Ethiraj, "Effect of calcination temperature on $\mathrm{Cu}$ doped $\mathrm{NiO}$ nanoparticles prepared via wet-chemical method: Structural, optical and morphological studies," Materials Science in Semiconductor Processing, vol. 66, pp. 149-156, 2017.

Q. P. Wang, D. H. Zhang, Z. Y. Xue, and X. J. Zhang, "Mechanisms of green emission from $\mathrm{ZnO}$ films prepared by rf magnetron sputtering," Optical Materials, vol. 26, pp. 23-26, 6// 2004.

[29] M. Jlassi, I. Sta, M. Hajji, and H. Ezzaouia, "Materials Science in Semiconductor Processing Optical and electrical properties of nickel oxide thin films synthesized by sol - gel spin coating," Materials Science in Semiconductor Processing, vol. 21, pp. 7-13, 2014.

[30] A. S. Ismail, M. H. Mamat, M. M. Yusoff, M. F. Malek, A. S. Zoolfakar, R. A. Rani, A. B. Suriani, A. Mohamed, M. K. Ahmad, and M. Rusop, "Enhanced humidity sensing performance using SnDoped $\mathrm{ZnO}$ nanorod Array/SnO2 nanowire heteronetwork fabricated via two-step solution immersion," Materials Letters, vol. 210, pp. 258-262, 2018/01/01/2018.

\section{AUTHORS PROFILE}

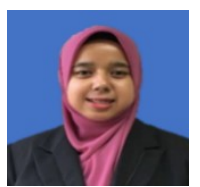

N.F.Q. Fahmi is a student at Universiti Teknologi MARA, Malaysia and currently pursuing her master's degree and working on metal-doped $\mathrm{NiO}$ humidity sensor. She received her bachelor's degree in Electronics Engineering from the same university.

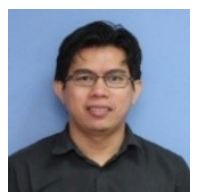

M. H. Mamat is an Associate Professor in Universiti Teknologi MARA, Malaysia. He currently working on research related nanodevices and the metal oxide semiconductor. He graduated from Nagoya University, Japan with a bachelor's degree in electrical \& electronic engineering and information engineering. He received his $\mathrm{PhD}$ and master's degrees in electrical engineering from Universiti Teknologi MARA, Malaysia.

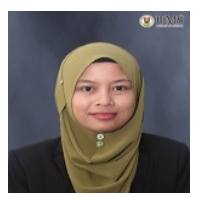

N. Parimon currently pursuing her $\mathrm{PhD}$ in Universiti Teknologi MARA, Malaysia. She is researching metalbased nanosensors. She is a lecturer at Universiti Malaysia Sabah, Malaysia. She graduated from Universiti Teknologi Malaysia, Malaysia and received both of her bachelor and master's degree in electrical and electronic and electrical engineering there.

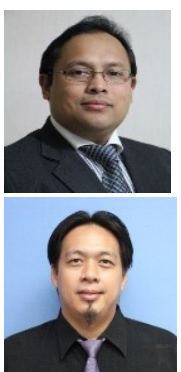

A.S. Zoolfakar an Associate Professor in Universiti Teknologi MARA, Malaysia. He received his bachelor and master's degree from University of Malaya, Malaysia and University of Liverpool, United Kingdom. He graduated from the University of RMIT and received his $\mathrm{PhD}$ in engineering.

A.H.A Razak an Associate Professor in Universiti Teknologi MARA, Malaysia. He currently working on IC Design fabrication and Embedded System Design.

I.B. Shameem Banu is a professor at B.S. Abdur Rahman Crescent Institute of Science and Technology, Chennai, India. She received two $\mathrm{PhD}$ in physics and $\mathrm{PhD}$ in condensed material physics from Madurai Kamaraj University, India and Anna University, Chennai, India.

M. Rusop currently a professor at Universiti Teknologi MARA, Malaysia. He graduated from Nagoya University, Japan and received his bachelor's degree there. He graduated from Nagoya Institute of Technology, Japan and received his master and $\mathrm{PhD}$ in engineering. 